\title{
Effect of Scopolamine-based Amnesia on the Number of Astrocytes in the Rat's Hippocampus
}

\author{
Efecto de la Amnesia Inducida por Escopolamina sobre el \\ Número de Astrocitos en el Hipocampo de Ratas \\ "Jahanshahi, M.; "**Azami, N. S. \& ${ }^{* * * * N i c k m a h z a r, ~ E . ~}$
}

JAHANSHAHI, M.; AZAMI, N. S. \& NICKMAHZAR, E. Effect of scopolamine-based amnesia on the number of astrocytes in the rat's hippocampus. Int. J. Morphol., 30(2):388-393, 2012.

SUMMARY: As neuron-astrocyte interactions play a crucial role in the adult brain, it is thought that astrocytes support learning and memory through specific mechanisms. In this study, the effect of scopolamine based amnesia on the number of astrocytes in rats' hippocampus was studied. Adult male albino Wistar rats were bilaterally cannulated into the CA1 region and animals received saline or different doses of scopolamine $(0.5,1 \mathrm{and} 2 \mathrm{mg} / \mathrm{rat}$, intra - CA1), immediately after training. Then all the rats were sacrificed and coronal sections were taken from the dorsal hippocampal formation of the right cerebral hemispheres and stained with PTAH. The area densities of the astrocytes in dentate gyrus were measured and compared in the all groups $(\mathrm{p}<0.05)$. Data showed that post-training scopolamine $(0.5,1$ and $2 \mu \mathrm{g} / \mathrm{rat}$, intra-CA1) dose-dependently reduced the step-through latency in the inhibitory avoidance task, showing scopolamineinduced amnesia. Also we found different response of astrocytes in different subfields of hippocampal formation. In dentate gyrus the number of astrocytes was increased, but in other areas scopolamine can decreased the density of astrocytes. We concluded that scopolamine can cause amnesia and this phenomenon can have an effect on astrocyte numbers in the rats hippocampal formation.

KEY WORDS: Scopolamine; Amnesia; Astrocyte; Hippocampus; Rat.

\section{INTRODUCTION}

Inhibitory avoidance tasks, which are widely used in pharmacological studies of long-term memory in rodents, have been anticipated to rely mainly on the dorsal hippocampus (Mahmoodi et al., 2010). As the cholinergic system plays an important role in learning and memory, a loss of cholinergic neurons and reduced choline acetyltransferase activity in the cerebral cortex and hippocampus are consistent with findings in Alzheimer's disease (Kwon et al., 2009). Alzheimer's disease (AD) is a progressive neurodegenerative disorder. AD patients have cognitive deficits, impaired long-term potentiation (LTP) and learning and memory (Cachard-Chastel et al., 2008).

The importance of cholinergic systems in learning and memory has been shown previously. Evidence suggested that acetylcholinesterase inhibitors, which enhance the availability of acetylcholine in the synaptic cleft improve performance in several cognitive models in both rodents and humans, whereas anticholinergic drugs impair learning and memory in a variety of tasks (Azami et al., 2010).
Scopolamine is a muscarinic cholinergic receptor antagonist that impairs memory performance that has been proposed as an animal model of dementia (Collerton, 1986; Jensen et al., 1987). Some similarities between Alzheimer patients and scopolamine treated animals in the memory deficits have been reported (Azami et al.). In addition, along with cholinergic atrophy, monoamines are reduced in Alzheimer's disease and the possibility may exist that enhancement of monoaminergic functions may elicit beneficial effects on behavior and cortical activity (Dringenberg, 2000).

In the past astrocytes were considered to be only of structural importance, but now the scientists believe that astrocytes play a essential role in brain functions, such as neuronal path finding, potassium buffering, $\mathrm{PH}$ regulation and production of energy substrates for neurons and also neurotransmitter synthesis and uptake (Emamian et al., 2009).

Neuron-astrocyte interactions play a crucial role during development and in the adult brain. Astrocytes

\footnotetext{
* Associated Professor of Anatomy, Neuroscience Research Center, Department of Anatomy, Golestaan University of medical Sciences, Gorgan, Iran. ** Assistant Professor of Physiology, Department of Biology, Gorgan Branch, Islamic Azad University, Gorgan, Iran.

**** Neuroscience Research Center, Golestan University of medical Sciences, Gorgan, Iran.
} 
modulate synaptic transmission, as well as the regulation of neurosteroidogenesis and neurogenesis (Jahanshahi et al., 2008; Emamian et al.).

Based on previous findings the aim of this study was to investigate the effects of bilateral microinjections of CA1 region of the dorsal hippocampus on scopolamine-induced amnesia and scopolamine state-dependent memory, by using an inhibitory avoidance task and also the number of astrocytes in different subfield of hippocampus after amnesia was investigated.

\section{MATERIAL AND METHOD}

Adult male ( 8 weeks) Wistar rats (Pasteur Institute, Tehran, Iran) weighing 220- 270 g were used. They were housed four in a cage and had free access to food and water, and kept at $(22 \pm 2)$ ?C under a 12/12 h light-dark cycle (light beginning at 7:00 a.m.). All experiments were carried out during the light phase between 8:00 and 14:00. Experimental groups consisted of eight animals and each animal was tested once.

Animals were anaesthetized intraperitoneally with a ketamine/xylazine mixture (100 and $10 \mathrm{mg} / \mathrm{kg}$, respectively) and placed in a stereotaxic frame (David Kopf Instruments, USA) with flat-skull position. A midline incision was made and the skin and underlying periosteum retracted. Stereotaxic coordinates for the CA1 regions of dorsal hippocampi were AP: $-3 \mathrm{~mm}$ from bregma, L: $\pm 2 \mathrm{~mm}$ from midline and V: $2.8 \mathrm{~mm}$ from the skull surface (Paxinos \& Watson, 2007). The cannulae were anchored to the skull with dental cement, and then stainless steel stylets (27 gauge) were inserted into the guide cannulae to maintain patency prior to microinfusions.

All procedures were performed in accordance with institutional guidelines for animal care and use.

Drugs and microinfusions.Scopolamine hydrobromide (Tocris, UK) was dissolved in sterile saline and injected into CA1 of dorsal hippocampus. For bilateral drug infusion, the animals were gently restrained by hand; the stylets were removed from the guide cannulae and replaced by 27 -gauge injection needles ( $1 \mathrm{~mm}$ below the tip of the guide cannula). The injection solutions were administered in a total volume of $1 \mathrm{ml} / \mathrm{rat}(0.5 \mathrm{ml}$ in each side $)$ over a $60 \mathrm{~s}$ period. Injection needles were left in place for an additional $60 \mathrm{~s}$ to facilitate the diffusion of the drugs (Azami et al.).

For behavioral test we used a step-through inhibitory avoidance apparatus consisted of two compartments of the same size $\left(20 \times 20 \times 30 \mathrm{~cm}^{3}\right)$. In the middle of a dividing wall, a guillotine door $\left(7.9 \mathrm{~cm}^{2}\right)$ could be lifted manually. The walls and floor of one compartment consisted of white opaque resin; the walls of the other compartment were dark. Stainless steel bars ( $3 \mathrm{~mm}$ in diameter and $1 \mathrm{~cm}$ intervals) constituted the floor of the dark compartment. Intermittent electric shocks $(50 \mathrm{~Hz}, 3 \mathrm{~s}, 1 \mathrm{~mA}$ intensity) were delivered to the grid floor of the dark compartment by an isolated stimulator (Azami et al.).

The method of our test was based on previous studies (Zarrindast et al., 2002, 2005). Effect of scopolamine on memory retrieval in this experiment, the effect of posttraining and pre-test administration of scopolamine on inhibitory avoidance response was examined. Four groups of animals received saline or different doses of scopolamine $(0.5,1$ and $2 \mathrm{mg} / \mathrm{rat}$, intra - CA1), immediately after training. On the test day, the animals received saline $(1 \mathrm{ml} / \mathrm{rat}$, intra CA1) 5 min before the test. The other groups of animals received saline $(1 \mathrm{ml} / \mathrm{rat}$, intra - CA1) or scopolamine (2 $\mathrm{mg} / \mathrm{rat}$, intra-CA1), immediately after training and pre-test ( $5 \mathrm{~min}$ before the test) injections of different doses of scopolamine $(0.5,1$ and $2 \mathrm{mg} /$ rat, intra - CA1).

Following behavioral testing, animals were decapitated under diethyl ether (Merck, Germany) anesthesia. Brains were removed and postfixed for 2 weeks in $10 \%$ formaldehyde for histological assessment. Next steps were dehydration using different degrees of alcohol and clarification with xylol. After histological processing, tissue was impregnated and then embedded in paraffin wax.

Histological and staining process was done on the brain sections of all six experimental groups. To quantify the number of astrocytes in the dentate gyrus, 15 slides from the proximity of cannula implantation region was obtained for each rat.

Finally, $7 \mu \mathrm{m}$ thick coronal slices were cut with a Leitz rotary microtome (HM 325, Microm International $\mathrm{GmbH}$, Walldorf, Germany). Mounted on slides, the last section of each 10 serial section was selected for staining; therefore, about 15 slides for morphometric measurement were obtained for each rat. Continuously, astrocytes were stained using phosphotanguestic acid hematoxylin (PTAH) (Jahanshahi, Sadeghi et al. 2008; Jahanshahi, Golalipour et al. 2009).

We preferred PTAH because it is the special staining method for astrocyte cell bodies and processes. In this method the astrocytes appear blue and the neurons become pink. Morphometric measurements were carried out using 
an Olympus DP 12 digital camera and BX 51 microscope (Olympus Optical, Tokyo, Japan). We selected a field (20,000 $\left.\mu \mathrm{m}^{2}\right)$ within the inferior horn of dentate gyrus.

Randomly selected, non-overlapping photographs were taken from the designated areas using a $40 ¥$ objective lens. Images were saved by the Bioreporter program and further processed using the Adobe Photoshop 6.0 program (Adobe System Inc., San Jose, CA, USA). For cell counts, photographs at a magnification of $40 \times$ (objective lens) were taken throughout the longitudinal axis of dentate gyrus and further processed as described above. All of the astrocytes shown on this field $\left(20,000 \mu \mathrm{m}^{2}\right)$ were counted. The mean average of number of astrocytes from 15 slides of each rat was calculated (Jahanshahi et al., 2008, 2009).

Data analysis. The data are expressed as mean \pm S.D. The statistical analysis was performed using one and two-way analysis of variance (ANOVA). Post-hoc comparison of means was carried out with the Tukey test for multiple comparisons, when appropriate. The level of statistical significance was set at $\mathrm{P}<0.05$. Calculations were performed using the SPSS statistical package.

\section{RESULTS}

Effects of Scopolamine on memory retrieval. Our data shows the effects of post-training or pre-test intra-CA1 administration of scopolamine on step-through latency. Oneway ANOVA revealed that post-training scopolamine $(0.5$, 1 and $2 \mu \mathrm{g} / \mathrm{rat}$, intra-CA1) dose-dependently reduced the step-through latency in the inhibitory avoidance task, showing scopolamine-induced amnesia. Furthermore, there was no significant difference between the number of trials to acquisition in animals that received scopolamine after training or before testing by itself and thus confirmed their uniformity (Fig. 1).

Effects of Scopolamine on hippocampal astrocytes. The mean and standard deviation of astrocytes in all groups showed in Tables (I, II and III). We found that in CA1 and CA3 areas of hippocampus the number of astrocytes decreased after exposure of scopolamine in all groups, and these differences were significant $(\mathrm{P}<0.05)$.

Our data showed that the differences of astrocytes

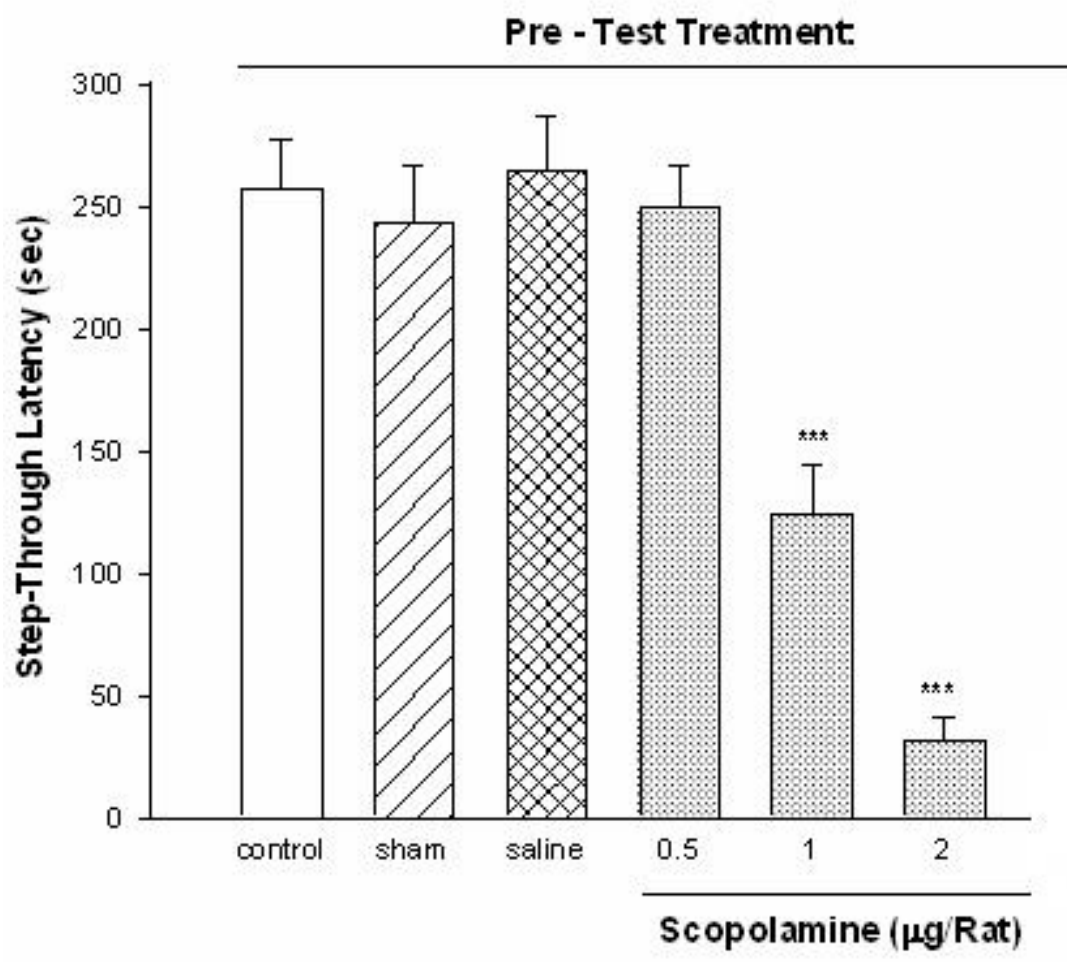

Fig. 1 indicates that animals in which retrieval was impaired due to post-training administration of scopolamine (scopolamine-induced amnesia), pre-test scopolamine $(0.5,1$ and $2 \mu \mathrm{g} / \mathrm{kg})$ restored the retrieval to the control level. 
Table I. The number of astrocytes of all groups in CA1 area Groups were compared with control.

\begin{tabular}{lccc}
\hline CA1 & Mean of astrocytes & Std. Deviation & P-Value \\
\hline Control & 19.03 & 5.44 & \\
Sham (surgery stress) & 11.15 & 3.65 & .000 \\
Sham saline-saline & 10.42 & 3.11 & .000 \\
Sco 2 - saline & 11.97 & 4.11 & .000 \\
Sco 1 - saline & 8.90 & 2.45 & .000 \\
Sco 0.5 - saline & 9.20 & 3.23 & .000 \\
Sco 2 - 2 & 8.82 & 2.91 & .000 \\
Sco 2 - 1 & 12.88 & 5.36 & .000 \\
Sco 2 - 0.5 & 9.70 & 3.36 & .000 \\
\hline
\end{tabular}

Table II. The number of astrocytes of all groups in CA3 area Groups were compared with control.

\begin{tabular}{lccc}
\hline CA3 & Mean of astrocytes & Std. Deviation & P-Value \\
\hline Control & 25.30 & 7.74 & \\
Sham (surgery stress) & 9.80 & 3.75 & .000 \\
Sham saline-saline & 10.68 & 2.85 & .000 \\
Sco 2 - saline & 12.63 & 5.66 & .000 \\
Sco 1 - saline & 9.23 & 1.91 & .000 \\
Sco 0.5 - saline & 9.38 & 3.24 & .000 \\
Sco 2 - 2 & 9.60 & 2.62 & .000 \\
Sco 2 - 1 & 12.25 & 5.49 & .000 \\
Sco 2 - 0.5 & 9.00 & 1.67 & .000 \\
\hline
\end{tabular}

Table III. The number of astrocytes of all groups in DG area Groups were compared with control.

\begin{tabular}{lccc}
\hline Dentate gyrus & Mean of astrocytes & Std. Deviation & P-Value \\
\hline Control & 17.02 & 6.50 & \\
Sham (surgery stress) & 35.88 & 14.03 & .000 \\
Sham saline-saline & 19.62 & 9.62 & .989 \\
Sco 2 - saline & 23.45 & 12.57 & .171 \\
Sco 1 - saline & 19.97 & 11.88 & .973 \\
Sco 0.5 - saline & 24.95 & 13.13 & .028 \\
Sco 2 - 2 & 20.15 & 8.43 & .959 \\
Sco 2 - 1 & 23.35 & 10.90 & .189 \\
Sco 2 - 0.5 & 13.28 & 6.39 & .873 \\
\hline
\end{tabular}

number in Dentate gyrus between control group with (17.02 \pm 6.5$)$ and surgery stress sham group with $(35.88 \pm 14.03)$ and also between control group and Sco2-0.5 group with (13.28 \pm 6.39$)$ were significant, but the differences of astrocytes number between control group and the other groups were not significant, however the density of astrocytes in these groups were more than the control group.

\section{DISCUSSION}

Step-through is a model of inhibitory avoidance task which is widely used in pharmacological studies of longterm memory in rodents (Izquierdo \& McGaugh, 2000; Izquierdo et al., 2006). The present data indicated that post-training or pre-test intra-CA1 administration of scopolamine by itself impaired memory retrieval on the test day. In agreement with our present studies, several lines of evidence have been reported that acetylcholine is a crucial mediator of learning and memory (Blokland, 1995).

As we show in dentate gyrus the density of astrocytes in all groups was increased but this increase in animals that affected in surgery stress was more than the other groups. This phenomenon probably is due to relationship between stress and astrocytes reaction. Also we found that the density of astrocytes in Sco 2-0.5 group decreased ratio to control group.

Also we found different response of astrocytes in different subfields of hippocampal formation. It seams in dentate gyrus following the neurogenesis phenomenon astrocytes increased, but in other areas scopolamine can decreased the density of astrocytes.

Several pharmacological studies showed that the scopolamine as muscarinic cholinergic receptor antagonist, causing destruction of memory and learning in different learning models, and this degradation is directly related to reduced cholinergic system performance (Bartus, 2000).

In this regard, some studies have shown that not only the reduced levels of acetylcholine, but also the increase in immune reactivity of IL-1b-induced betaamyloid peptide Ab1-42, caused defects in learning and memory. IL-1 released from astrocytes in culture medium inhibits long-term memory in the hippocampus. Therefore, the correlation between the 
number of immunoreactive astrocytes to GFAP and spatial memory deficit has also been reported (Yan et al., 2001).

Other studies showed that injection of a-GPC (cholinergic precursors) before the behavioral test of learning prevent deficit caused by scopolamine, because it is possible that scopolamine associated with increased synthesis and release of acetylcholine in hippocampus. Treatment with aGPC reduce glial reaction levels in the hippocampus that it is possible to cause neuronal protection and astroglial dynamic effects and some important neurodegenerative disorders such as brain aging, stroke, ischemic brain disease Parkinson's and Alzheimer's to be effective (Bramanti et al., 2008).

As was stated earlier the scopolamine induced amnesia. Many studies have shown that Alzheimer's disease is associated with neuronal apoptosis. Recently, Bcl-2 gene as a major inhibitor of apoptosis considered that associated with learning and memory ability is the central nervous system (Niu et al., 2007).

About that the mechanisms associated with the effect of scopolamine in 2005, Zhong et al. (2005) showed that potassium channels are important to regulate neuronal excitability and synaptic transmission. Several studies in various experimental models have proven important role of potassium channels in learning and memory mechanisms.

In conclusion, considering the results, it can be concluded that a dose-dependent scopolamine $(0.5,1,2 \mu \mathrm{g}$ / rat, intra-CA1) injections, after training or before testing, reduces the delay of arrival in black chamber of passive avoidance, this is represents scopolamine induced amnesia. Also we concluded that the scopolamine have different effect on the number of astrocytes in different subfields of hippocampus.

JAHANSHAHI, M.; AZAMI, N. S. \& NICKMAHZAR, E. Efecto de la amnesia inducida por escopolamina sobre el número de astrocitos en el hipocampo de ratas. Int. J. Morphol., 30(2):388-393, 2012.

RESUMEN: Las interacciones neuronas-astrocitos desempeñan un papel crucial en el cerebro adulto, y se cree que los astrocitos apoyan el aprendizaje y la memoria a través de mecanismos específicos. Fue estudiado el efecto de amnesia inducida por escopolamina en el número de astrocitos del hipocampo de ratas. Ratas Wistar albinas macho adultas fueron canuladas bilateralmente en la región CA1 recibiendo solución salina o diferentes dosis de escopolamina $(0,5,1$ y $2 \mathrm{mg} / \mathrm{rata}$, intra - CA1), inmediatamente después del entrenamiento. Luego, todas las ratas se sacrificaron y se tomaron secciones coronales de la formación del hipocampo dorsal del hemisferio cerebral derecho y se tiñeron con PTAH. Las densidades de área de los astrocitos en el giro dentado fueron medidas y comparadas en todos los grupos ( $\mathrm{p}<0,05)$. Los datos mostraron que la escopolamina $(0,5,1 \mathrm{y} 2 \mathrm{mg} / \mathrm{rata}$, intra-CA1) dosis-dependiente post-entrenamiento redujo el paso de latencia de la tarea de evitación inhibitoria, mostrando amnesia inducida por escopolamina. También encontramos diferentes respuestas de los astrocitos en los distintos subcampos de la formación hipocampal. En el giro dentado, el número de astrocitos se incrementó, pero en otras áreas la escopolamina pudo disminuir la densidad de los astrocitos. Se concluye que la escopolamina puede causar amnesia y este fenómeno puede afectar el número astrocitos en la formación hipocampal de ratas.

PALABRAS CLAVE: Escopolamina; Amnesia; Astrocitos; Hipocampo; Rata.

\section{REFERENCES}

Azami, N. S.; Piri, M.; Oryan, S.; Jahanshahi, M.; Babapour, V. \& Zarrindast, M. R. Involvement of dorsal hippocampal alphaadrenergic receptors in the effect of scopolamine on memory retrieval in inhibitory avoidance task. Neurobiol. Learn. Mem., 93(4):455-62, 2010

Bartus, R. T. On neurodegenerative diseases, models, and treatment strategies: lessons learned and lessons forgotten a generation following the cholinergic hypothesis. Exp. Neurol., 163(2):495$529,2000$.

Blokland, A. Acetylcholine: a neurotransmitter for learning and memory? Brain Res. Brain Res. Rev., 21(3):285-300, 1995.

Bramanti, V.; Campisi, A.; Tomassoni, D.; Li Volti, G.; Caccamo, D.; Cannavò, G.; Currò, M.; Raciti, G.; Napoli, M.; Ientile, R.; Vanella, A.; Amenta, F. \& Avola, R. Effect of acetylcholine precursors on proliferation and differentiation of astroglial cells in primary cultures. Neurochem. Res., 33(12):2601-8, 2008.

Cachard-Chastel, M.; Devers, S.; Sicsic, S.; Langlois, M.; Lezoualc'h, F.; Gardier, A. M. \& Belzung, C. Prucalopride and donepezil act synergistically to reverse scopolamine-induced memory deficit in C57B1/6j mice. Behav. Brain Res., 187(2):455-61, 2008.

Collerton, D. Cholinergic function and intellectual decline in Alzheimer's disease. Neuroscience, 19(1):1-28, 1986.

Dringenberg, H. C. Alzheimer's disease: more than a 'cholinergic disorder' - evidence that cholinergic-monoaminergic interactions contribute to EEG slowing and dementia. Behav. Brain Res., 115(2):235-49, 2000. 
Emamian, S.; Naghdi, N.; Sepehri, H.; Jahanshahi, M.; Sadeghi, Y. \& Choopani, S. Learning impairment caused by intra-CA1 microinjection of testosterone increases the number of astrocytes. Behav. Brain Res., 208(1):30-7, 2010.

Izquierdo, I.; Bevilaqua, L. R.; Rossato, J. I.; Bonini, J. S.; Medina, J. H. \& Cammarota, M. Different molecular cascades in different sites of the brain control memory consolidation. Trends Neurosci., 29(9):496-505, 2006.

Izquierdo, I. \& McGaugh, J. L. Behavioural pharmacology and its contribution to the molecular basis of memory consolidation. Behav. Pharmacol., 11(7-8):517-34, 2000.

Jahanshahi, M.; Golalipour, M. J. \& Afshar, M. The effect of Urtica dioica extract on the number of astrocytes in the dentate gyrus of diabetic rats. Folia Morphol., 68(2):93-7, 2009.

Jahanshahi, M.; Sadeghi, Y.; Hosseini, A.; Naghdi, N. \& Marjani, A. The effect of spatial learning on the number of astrocytes in the CA3 subfield of the rat hippocampus. Singapore Med. J., 49(5):388-91, 2008.

Jensen, L. H.; Stephens, D. N.; Sarter, M. \& Petersen, E. N. Bidirectional effects of beta-carbolines and benzodiazepines on cognitive processes. Brain Res. Bull., 19(3):359-64, 1987.

Kwon, S. H.; Kim, H. C.; Lee, S. Y. \& Jang, C. G. Loganin improves learning and memory impairments induced by scopolamine in mice. Eur. J. Pharmacol., 619(1-3):44-9, 2009.

Mahmoodi, G.; Ahmadi, S.; Pourmotabbed, A.; Oryan, S. \& Zarrindast, M. R. Inhibitory avoidance memory deficit induced by scopolamine: Interaction of cholinergic and glutamatergic systems in the ventral tegmental area. Neurobiol. Learn. Mem., 94(1):83-90, 2010.

Niu, Q.; Yang, Y.; Zhang, Q.; Niu, P.; He, S.; Di Gioacchino, M.; Conti, P. \& Boscolo, P. The relationship between Bcl-gene expression and learning and memory impairment in chronic aluminum-exposed rats. Neurotox. Res., 12(3):163-9, 2007.

Paxinos, G. \& Watson, C. The rat brain in stereotaxic coordinates. San Diego, Academic press. 2007.

Yan, J. J.; Cho, J. Y.; Kim, H. S.; Kim, K. L.; Jung, J. S.; Huh, S. O.; Suh, H. W.; Kim, Y. H. \& Song, D. K. Protection against beta-amyloid peptide toxicity in vivo with long-term administration of ferulic acid. Br. J. Pharmacol., 133(1):8996, 2001.

Zarrindast, M. R.; Bakhsha, A.; Rostami, P. \& Shafaghi, B. Effects of intrahippocampal injection of GABAergic drugs on memory retention of passive avoidance learning in rats. $J$. Psychopharmacol., 16(4):313-9, 2002.

Zarrindast, M. R.; Farajzadeh, Z.; Rostami, P.; Rezayof, A. \& Nourjah, P. Involvement of the ventral tegmental area (VTA) in morphine-induced memory retention in morphine-sensitized rats. Behav. Brain. Res., 163(1):100-6, 2005.

Zhong, C. B.; Pan, Y. P.; Tong, X. Y.; Xu, X. H. \& Wang, X. L. Delayed rectifier potassium currents and Kv2.1 mRNA increase in hippocampal neurons of scopolamine-induced memorydeficient rats. Neurosci. Lett., 373(2):99-104, 2005.

\section{Correspondence to: \\ Dr. Mehrdad Jahanshahi \\ Neuroscience Research Center \\ Department of Anatomy, Faculty of Medicine \\ Golestan University of Medical Sciences \\ Km 4 Gorgan-Sari road (Shastcola), Gorgan \\ IRAN}

Tel: 0098-171-4421717

P.O. Box: 49175-553

E-mail: mejahanshahi@yahoo.com

Received: 11-09-2011

Accepted: 14-11-2011 